OPEN ACCESS

Edited by:

Catherine Sautes-Fridman, INSERM U1138 Centre de Recherche des Cordeliers, France

Reviewed by: William K. Decker, Baylor College of Medicine United States Bruce Loveland, Burnet Institute, Australia

*Correspondence: Rasha Abu Eid rasha.abueid@abdn.ac.uk

Specialty section: This article was submitted to Cancer Immunity and Immunotherapy,

a section of the journal

Frontiers in Oncology

Received: 30 May 2018 Accepted: 21 September 2018 Published: 15 October 2018

Citation:

O'Higgins C, Ward FJ and Abu Eid R (2018) Deciphering the Role of Regulatory CD4 T Cells in Oral and Oropharyngeal Cancer: A Systematic

Review. Front. Oncol. 8:442. doi: 10.3389/fonc. 2018.00442

\section{Deciphering the Role of Regulatory CD4 T Cells in Oral and Oropharyngeal Cancer: A Systematic Review}

\author{
Caoimhín O'Higgins ${ }^{1}$, Frank J. Ward ${ }^{2}$ and Rasha Abu Eid ${ }^{1,2 *}$ \\ ${ }^{1}$ Institute of Dentistry, School of Medicine, Medical Sciences and Nutrition, University of Aberdeen, Aberdeen, Scotland, \\ ${ }^{2}$ Institute of Medical Sciences, School of Medicine, Medical Sciences and Nutrition, University of Aberdeen, Aberdeen, \\ Scotland
}

Background: Recruiting regulatory CD4 T cells (Tregs) into the tumor microenvironment is an important tumor escape mechanism. Diminishing these suppressive cells is therefore one of the targets of cancer immunotherapy. Selective depletion of Tregs has proven successful in enhancing anti-tumor immunity and therapeutic efficacy in multiple tumor types. However, the role of Tregs in oral/oropharyngeal cancers is unclear with conflicting evidence regarding the effect of these suppressive cells on tumor prognosis. In this study, we sought to review the role of Tregs in oral/oropharyngeal cancer with the aim of deciphering the controversy regarding their effect on tumor progression and prognosis.

Methods: A systematic review of the literature pertaining to the role of Tregs in oral/oropharyngeal cancer was performed using Scopus, Embase, and PubMed. Forty-five records were deemed eligible and data describing methodology of Treg detection, tumor type, and association with prognosis were extracted.

Results: Of the 45 eligible manuscripts accepted for this systematic review, thirty-nine studies reported data from human subjects while the remaining studies focused on animal models. Sixteen studies were carried out using peripheral blood samples, while samples from the tumor site were analyzed in 18 studies and 11 studies assessed both blood and tumor samples. The transcriptional factor, Foxp3, was the most commonly used marker for Treg identification (38/45). The findings of 25 studies suggested that an increase in Tregs in the tumor microenvironment and/or peripheral blood was associated with poorer prognosis. These conclusions were attributed to the suppression of immune responses and the consequent tumor progression. Conversely, nine studies showed an increase in Tregs in peripheral blood and/or tumor microenvironment was related to a favorable prognosis, particularly in the presence of human papilloma virus (HPV), the status of which was only assessed in 11 studies. 
Conclusions: This review underlines the importance of host immunity in the behavior of oral/oropharyngeal cancer. Furthermore, we report an apparent lack of clarity regarding the true role Tregs play in oral/oropharyngeal cancer progression which could be attributed to inconsistent detection techniques of Tregs. Our results therefore highlight the need for clearer methodologies and more robust phenotyping when defining Tregs.

Keywords: regulatory T cells, oral cancer, oropharyngeal cancer, patient outcome, tumor microenvironment

\section{INTRODUCTION}

Head and neck cancer is the sixth most common malignancy with an estimated 686,000 new cases and 375,000 deaths reported annually (combined worldwide laryngeal, oral, and pharyngeal cancer incidence) (1). The majority of head and neck cancers are squamous cell carcinoma (SCC). Along with alcohol consumption, smoking and various forms of betel quid chewing [which have long been associated with the development of oral and oropharyngeal squamous cell carcinoma (OPSCC)], it is now recognized that human papilloma virus (HPV) infection plays an important role in the onset of HPV positive OPSCC (2).

Despite advances in diagnosis and treatment, OPSCC mortality rate has improved little over the years, with 5 year survival rates as low as 53\% reported in England for cancers of the oral cavity (3). This is mainly attributed to late diagnosis and the absence of predictors of disease progression in oral premalignant lesions.

Recently a growing emphasis is being placed on the role of the immune system and its association with the occurrence and progression of cancer. Indeed, cancer immunotherapy is among the most important developments in cancer treatment. It was therefore not surprising that cancer immunotherapy was named the scientific breakthrough of the year in 2013 (4). Despite the impressive successes in cancer immunotherapy, the response in patients is sometimes short lived. This is due to factors that hamper the immune response against cancer such as the presence of the suppressive regulatory CD4 T cells (Tregs) in the tumor microenvironment (5).

Tregs are a subpopulation of $\mathrm{CD} 4^{+} \mathrm{T}$ lymphocytes which are capable of discerning self-antigens from non-self-antigens and suppressing the expansion of effector cells directed against self. The major subpopulations of Tregs include thymus-derived Tregs (tTregs), Tregs which have been induced peripherally by different cytokines (pTregs), and induced Tregs which are induced in vitro in the lab, (iTregs). All Treg types maintain regulatory functions, and their development and function are thought to be dependent on the expression of the transcription factor Forkhead box P3 (FoxP3), known as the "master regulator" of Treg regulatory functions $(6,7)$.

Within the tumor microenvironment, Tregs have an opposing action to cytotoxic CD8 $\mathrm{T}$ cells (8), and reducing the number of Tregs was found to reinvigorate anti-tumor immunity and promote tumor regression in different types of cancer (9-14).

The role of Tregs in oral/oropharyngeal cancer is not fully understood and different studies have reported conflicting evidence regarding the role of Tregs in oral/oropharyngeal cancer progression and prognosis. Some studies emphasized the suppressive role of Tregs within the tumor microenvironment or the periphery, thus negatively impacting the patient clinical outcome (15-20), others reported a positive clinical outcome associated with an increase in circulating or tumor infiltrating Treg (21-29).

It is therefore important to fully comprehend the causes of these contradictions to enable full understanding of the role that Tregs play in oral/oropharyngeal cancer. This will enable designing novel immune-therapeutics that optimize the anti-tumor immune response and ultimately clinical outcome.

In this study, we sought to review the role of Tregs in oral/oropharyngeal cancer with the aim of deciphering the controversy regarding their effect on tumor progression and patient prognosis.

\section{METHODS}

We conducted and reported this systematic review following the PRISMA statement (30).

\section{Search Strategy}

A systematic search of PubMed, Embase, and Scopus (from their commencements to May 2017 when the search was performed), for studies in the English language with no species restrictions and for studies related to the role of Tregs in oral and oropharyngeal cancer. The following keywords were used in searching: ("head and neck cancer" or "head and neck malignancy" or "oropharyngeal") and ("epithelial dysplasia" or "oropharyngeal premalignancy") and ("tumor microenvironment" or "cancer immunology" or "tumor infiltrating lymphocytes" or "TILs" or "circulating immune cells" or "peripheral immune cells") and ("regulatory $\mathrm{T}$ cells" or "regulatory T lymphocyte" or "regulatory CD4 T lymphocyte" or "regulatory CD4 T cells" or "Treg" or "Tregs" or "Foxp3+ or CD4+Foxp3+" or "CD25+" or "CD4+CD25+" or "suppressive immune cells" or "suppressive lymphocytes").

We scrutinized the reference lists of the identified reports, reviews, meta-analyses, and other relevant publications to find additional pertinent studies. The "related articles" function was also used to broaden the search.

Our inclusion criteria were:

1- Studies must have been published as original articles

2- Studies must have been published in English

3- Studies assessing the role of Tregs in oral and oropharyngeal cancer. 


\section{Our exclusion criteria were:}

1- Letters to the editor, conference abstracts, review, and systemic review articles

2- Studies that focused on thyroid, laryngeal, esophageal, and salivary gland tumors.

\section{Data Extraction}

The studies which met the inclusion criteria were summarized and data extraction was performed using a pre-defined form by one of the authors (CO) and accuracy checks were performed on over $75 \%$ of the manuscripts by (RA). Data extracted included: author, journal, year of publication, sample size, tumor type, tumor site, species, whether blood or tumor sample were used, method of sample analysis, markers used to detect Tregs, role of Tregs in tumor progression/prognosis, HPV status, correlations between HPV status and Tregs, tTregs vs. pTregs, and any data related to oral epithelial dysplasia.

Due to the huge variation in the study designs, the number of samples, the tumor site, and the method for detecting Tregs within tumor or blood samples, meta analyses of the results were not possible.

\section{RESULTS}

\section{Manuscripts Included in the Systematic Review}

Of 715 identified citations, we identified 54 articles which met the inclusion criteria. Following full text screening, 45 articles were deemed to be eligible for inclusion in this study. Reasons for exclusion included irrelevant manuscripts which did not tackle the role of Tregs in oral and oropharyngeal cancer $(n=478)$, manuscripts that focused on tumors other than oral or oropharyngeal; laryngeal/esophageal $(n=82)$, salivary gland $(n=44)$, thyroid gland $(n=32)$ or gastric tumors $(n=18)$, review articles $(n=13)$, one study looked at the role of Tregs in periodontal disease and two articles were excluded because they assessed the expression of Foxp3 in tumor cells rather than assessing Tregs. Figure 1 shows the flow diagram of the studies retrieved for this systematic review.

\section{Data Summary}

The full characteristics of the study populations are displayed in Table 1.

\section{Tumors}

The majority of the studies $[n=39(86.7 \%)]$ assessed human samples $(15-18,20-29,31,33,36-40,42-51,54-60)$, one study assessed both human and murine samples (32), two studies looked at murine samples $(19,34)$, one at rat $(41)$, and two at canine samples $(52,53)$. With the exception of two studies that looked into multiple myeloma in canines $(52,53)$, all studies focused on oral and/or oropharyngeal SCC $[n=43(95.5 \%)]$. Within the 45 studies, the site of the tumor varied and included tumors of the oral cavity (tongue, floor of the mouth, base of the tongue, gingiva), oropharynx, hypopharynx, lower lip, tonsil, epipharynx, and lymph node metastasis. Three studies used head and neck cancer cell lines $(19,40,58)$.

Table 2 details the methodologies used to detect Tregs, the markers used and the changes in Tregs observed with treatment and with disease progression. Table 2 also summarizes the suggested role of Tregs in oral and oropharyngeal cancer for each included manuscript.

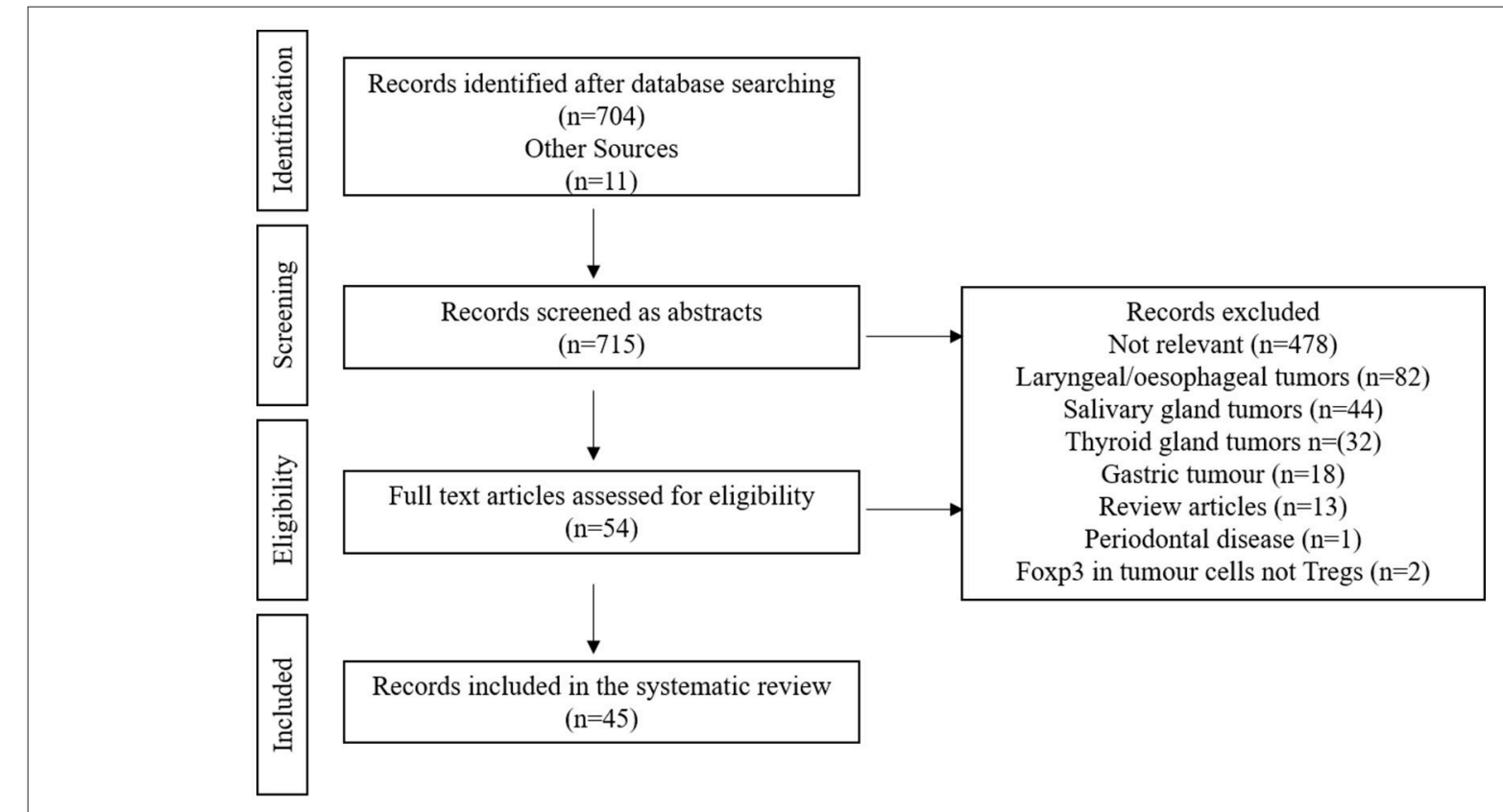

FIGURE 1 | Flow diagram of the studies retrieved for the review. 
TABLE 1 | Basic information about the 45 studies that met the inclusion criteria for this systematic review.

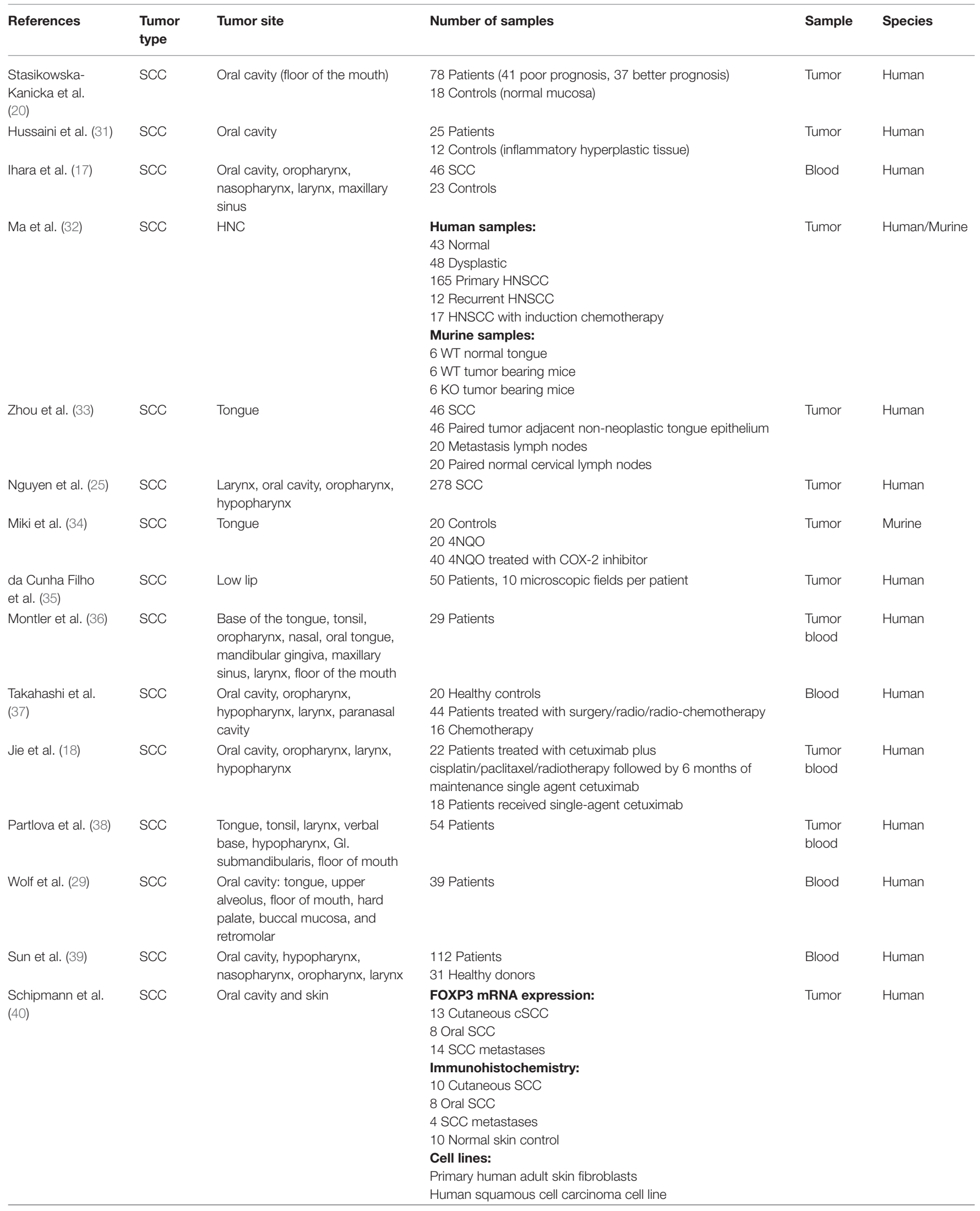


TABLE 1 | Continued

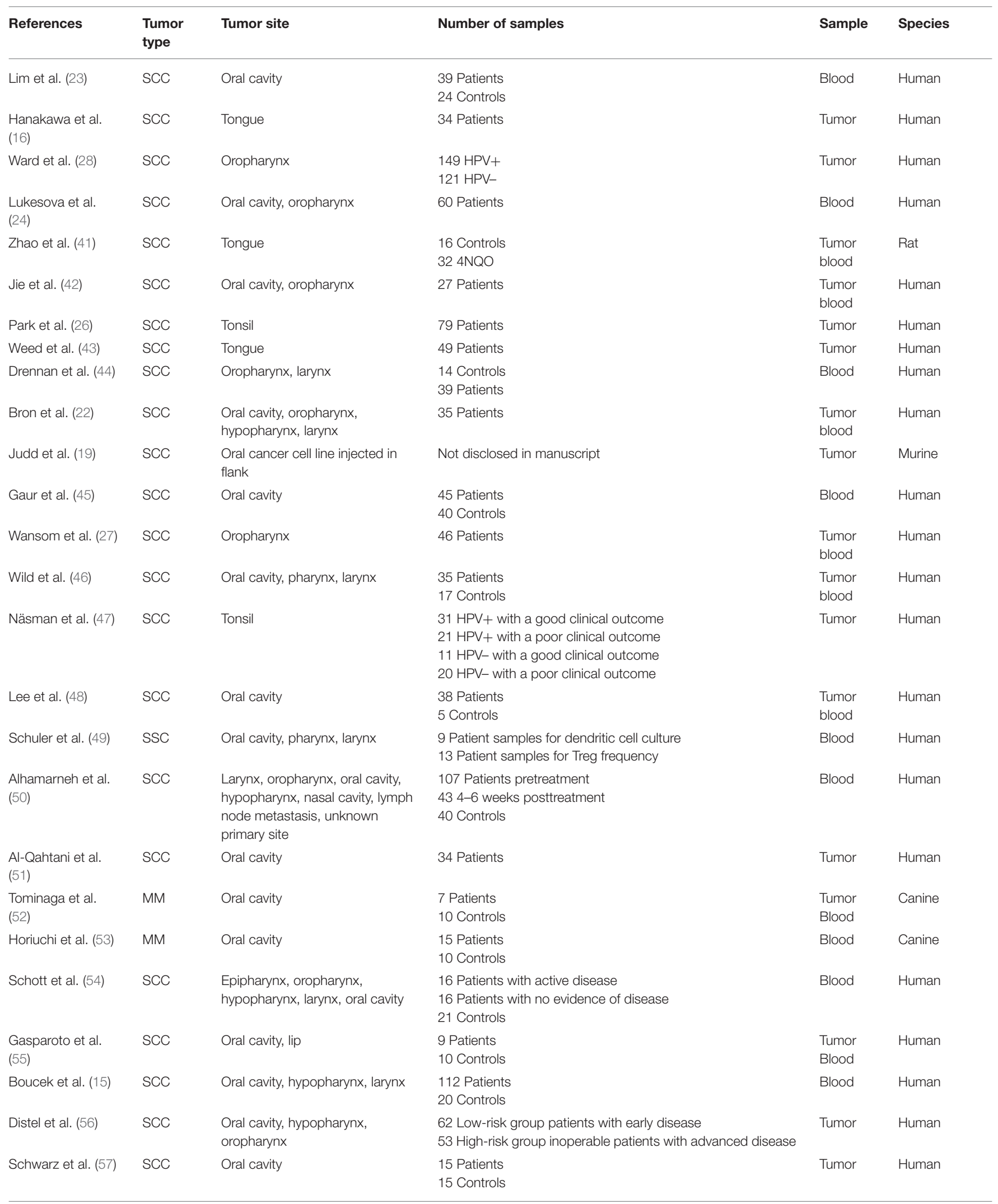


TABLE 1 | Continued

\begin{tabular}{|c|c|c|c|c|c|}
\hline References & $\begin{array}{l}\text { Tumor } \\
\text { type }\end{array}$ & Tumor site & Number of samples & Sample & Species \\
\hline $\begin{array}{l}\text { Bergmann et al. } \\
\text { (58) }\end{array}$ & SCC & $\begin{array}{l}\text { HNSCC cell lines from primary } \\
\text { tumors }\end{array}$ & $\begin{array}{l}\text { Cell culture of irradiated HNSCC cell lines from primary } \\
\text { tumors with blood samples from } 10 \text { healthy donors }\end{array}$ & Blood & Human \\
\hline $\begin{array}{l}\text { Chikamatsu et al. } \\
\text { (59) }\end{array}$ & SCC & $\begin{array}{l}\text { Oral cavity, oropharynx, } \\
\text { hypopharynx, larynx, paranasal } \\
\text { sinuses }\end{array}$ & $\begin{array}{l}43 \text { Patients } \\
24 \text { Controls }\end{array}$ & Blood & Human \\
\hline Badoual et al. (21) & SCC & $\begin{array}{l}\text { Oral cavity, oropharynx, } \\
\text { hypopharynx }\end{array}$ & 84 Patients & Tumor & Human \\
\hline Schaefer et al. (60) & SCC & $\begin{array}{l}\text { Larynx, oral cavity, pharynx, } \\
\text { hypopharynx }\end{array}$ & $\begin{array}{l}24 \text { Patients } \\
17 \text { Controls }\end{array}$ & Blood & Human \\
\hline
\end{tabular}

SCC, Squamous Cell Carcinoma; MM, Multiple Myeloma; HNC, Head and Neck Cancer; HNSCC, Head and Neck Squamous Cell Carcinoma.

\section{Samples and Treg Analyses}

Eighteen studies assessed tumor samples (16, 19-21, 25, 26, $28,31-35,40,43,47,51,56,57), 16$ assessed blood samples $(15,17,23,24,29,37,39,44,45,49,50,53,54,58-60)$, and 11 studies assessed both tumor and blood samples (18, 22, 27, 36, $38,41,42,46,48,52,55)$.

With regards to the methodologies used to detect and assess Tregs, immunohistochemistry was used in 21 studies $(16,20,22$, $24-29,31-36,40,47,48,51,56,57)$, flow cytometry in 25 studies $(15,17-19,23,24,32,36-39,41,42,44-46,48-50,52-55,58-$ $60)$, Immunofluorescence in six studies $(21,31,32,43,46,52)$, PCR in six studies $(24,34,38,40,46,48)$, ELISA in four studies $(23,46,50,58)$, Histopathology and morphology in three studies $(20,34,35)$, and Western blots in two studies $(32,58)$. The majority of the studies ( 30 out of 45 studies) used only a single method for detecting Tregs (15-19, 21, 22, 25-29, 33, 37, 39, 41$45,47,49,51,53-57,59,60)$. The most common single method was flow cytometry (16 out of 30$)(15,17-19,37,39,41,42,44$, $45,49,53-55,59,60)$, followed by immunohistochemistry (12 out of 30$)(16,22,25-29,33,47,51,56,57)$ and immunofluorescence was used as a single method for Treg detection in two studies $(21,43)$. Eight out of the 45 studies used two methods of Treg assessment $(20,23,31,35,36,40,50,52)$ while seven studies used three or more methodologies $(24,32,34,38,46,48$, 58).

As for the markers used to detect Tregs and assess their function, Foxp3 was the most commonly used marker, as it was used in 38 out of the 45 studies (16-22, 25-29, 31-36, 39-43, 45$58,60)$. Foxp 3 was the sole marker for Treg detection in 13 studies $(16,20,22,25,27-29,34,35,40,47,51,56)$. Foxp3 in combination with T cell markers CD3, CD4, and/or CD25, was used as a marker in 14 studies $(15,19,24,26,33,41,43,45$, $49,52,53,57,59$ ). CD25 was used as a marker (on its own or with other markers) in 24 studies $(15,18,21,23,24,26,36-$ $39,41,42,44-46,48-50,54,55,58-60)$. Seven studies identified Tregs using a combination of CD $4+\mathrm{CD} 25+\mathrm{CD} 127^{\text {low }}$ with or without other markers $(17,23,37,38,44,46,54)$. CTLA-4 was used as a marker of Treg phenotype or suppressive function in seven studies $(18,36,42,50,54,55,58)$, GITR was assessed in four studies and as a marker of Treg function $(50,54,55,60)$, TGF- $\beta$ was assessed in four studies $(18,42,48,55)$, and IL-10 was used in two studies $(55,58)$.

\section{HPV Status}

Only 11 manuscripts looked at the HPV status of the tumors (24-29, 32, 36, 38, 43, 47), and out of those, only 10 included HPV positive cases in their studies $(24-29,32,36,38,47)$. Half these studies reported no difference in Treg levels between HPV positive and negative tumors (24, 27, 29, 32, 36). Two manuscripts reported a decrease in Treg proportion in HPV positive $(28,38)$ [one associated with an increase in TIL (28)], and three reported an increase in Treg associated with an overall increase in TIL $(24,25,47)$. Four studies associated HPV positive tumors with better survival compared to HPV negative $(24,27$, $28,47)$. One study found no correlation between HPV status and survival (29). Three studies correlated an increase in Tregs in HPV positive tumors with better prognosis $(24,26,28)$, however, one of the studies suggested that it was associated with the overall increase in TIL (28).

\section{Correlation of Tregs With Clinical Outcome}

Twenty-four studies reported a clear increase in Tregs (whether intratumoral or circulating) in cancer patients in comparison to healthy controls and/or in more advanced disease $(15,20,23,31-$ $34,37,39-41,44,45,48-55,57,59,60)$. Only three studies reported a decrease in Tregs with more advanced disease (22, 29, 35).

Out of the 45 papers included in this study, 25 studies (55.6\%) found a correlation between Tregs and poor clinical outcome and disease progression $(15-20,32,33,37,39-42,44-46,48$, $49,51-55,58,59)$, nine manuscripts $(20 \%)$ correlated Tregs to good clinical outcome (21-29), and 11 (24.4\%) did not reach a conclusion regarding the role of Tregs in tumor progression $(31,34-36,38,43,47,50,56,57,60)$.

No apparent correlation was found between the site of the tumor and the outcome. Only one study reported higher numbers of Tregs in Oral SCC lesions in comparison to oropharyngeal tumors (24).

With regards to the type of samples assessed for Tregs, interestingly, the majority of the studies that could not conclude the role of Tregs [7 out of 11 studies (63.6\%)] looked only at tumor samples $(31,34,35,43,47,56,57)$. Four of the studies that only assessed tumor samples showed an association between Tregs and good prognosis (21, 25, 26, 28), while seven showed association with poor prognosis and clinical 


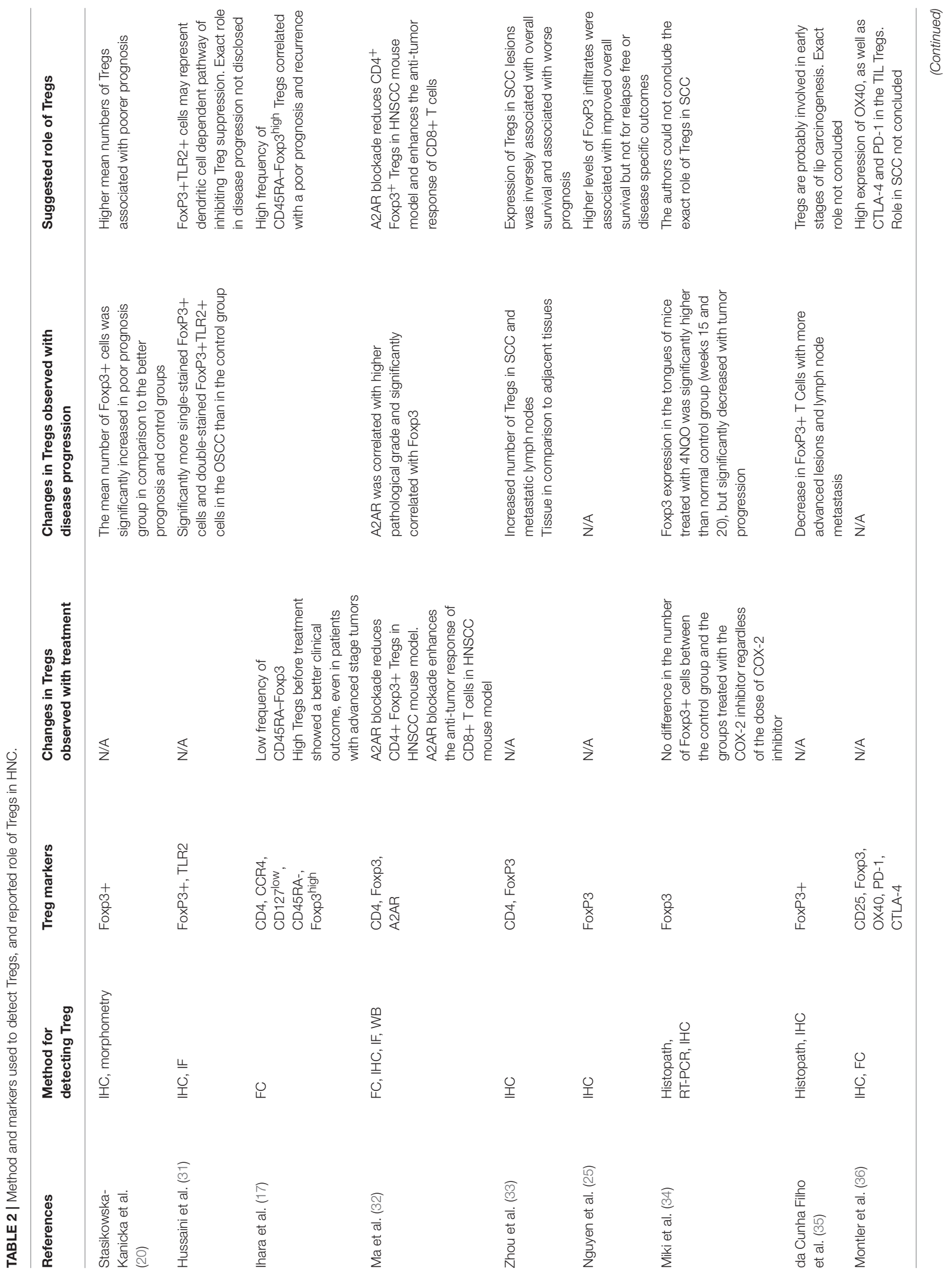




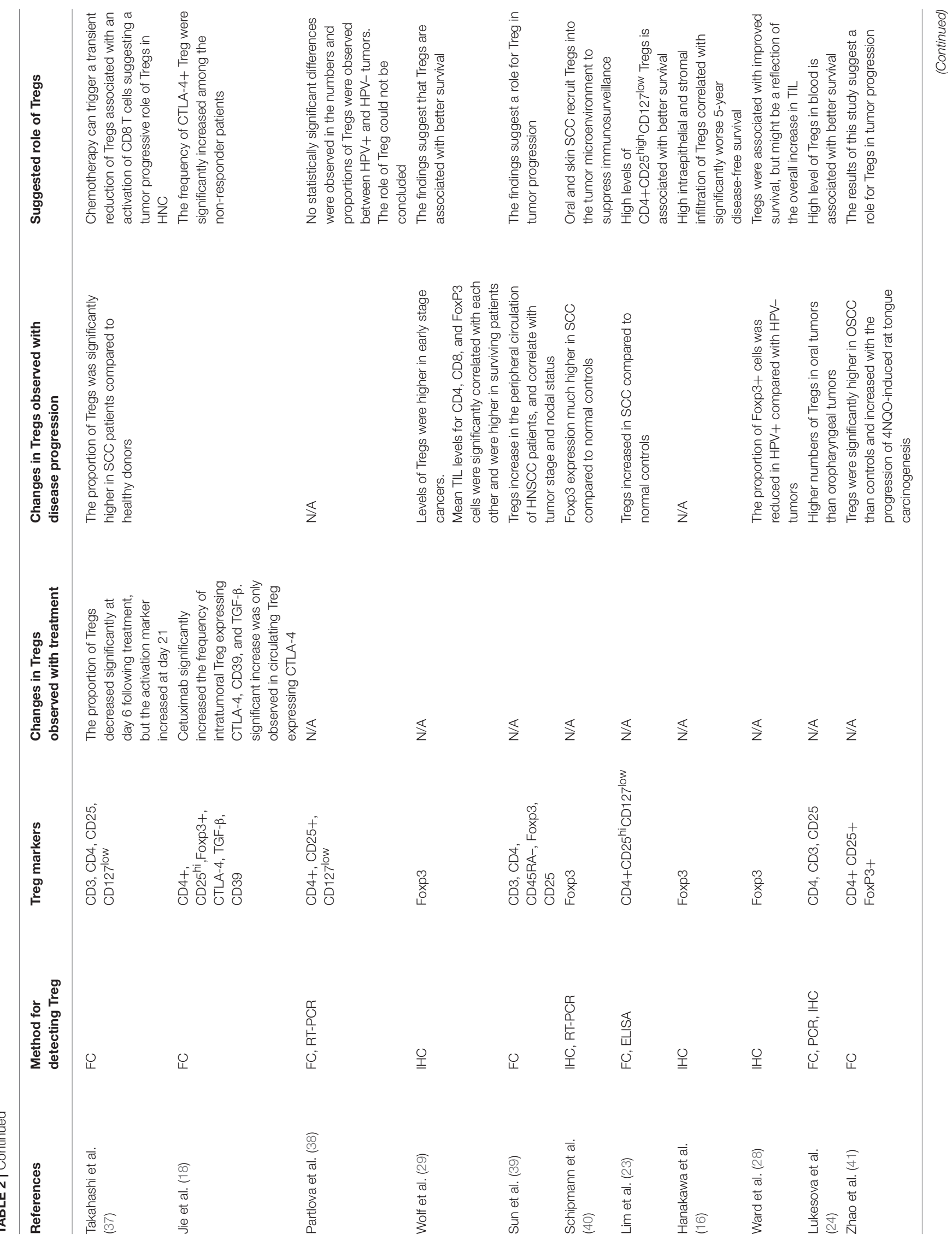




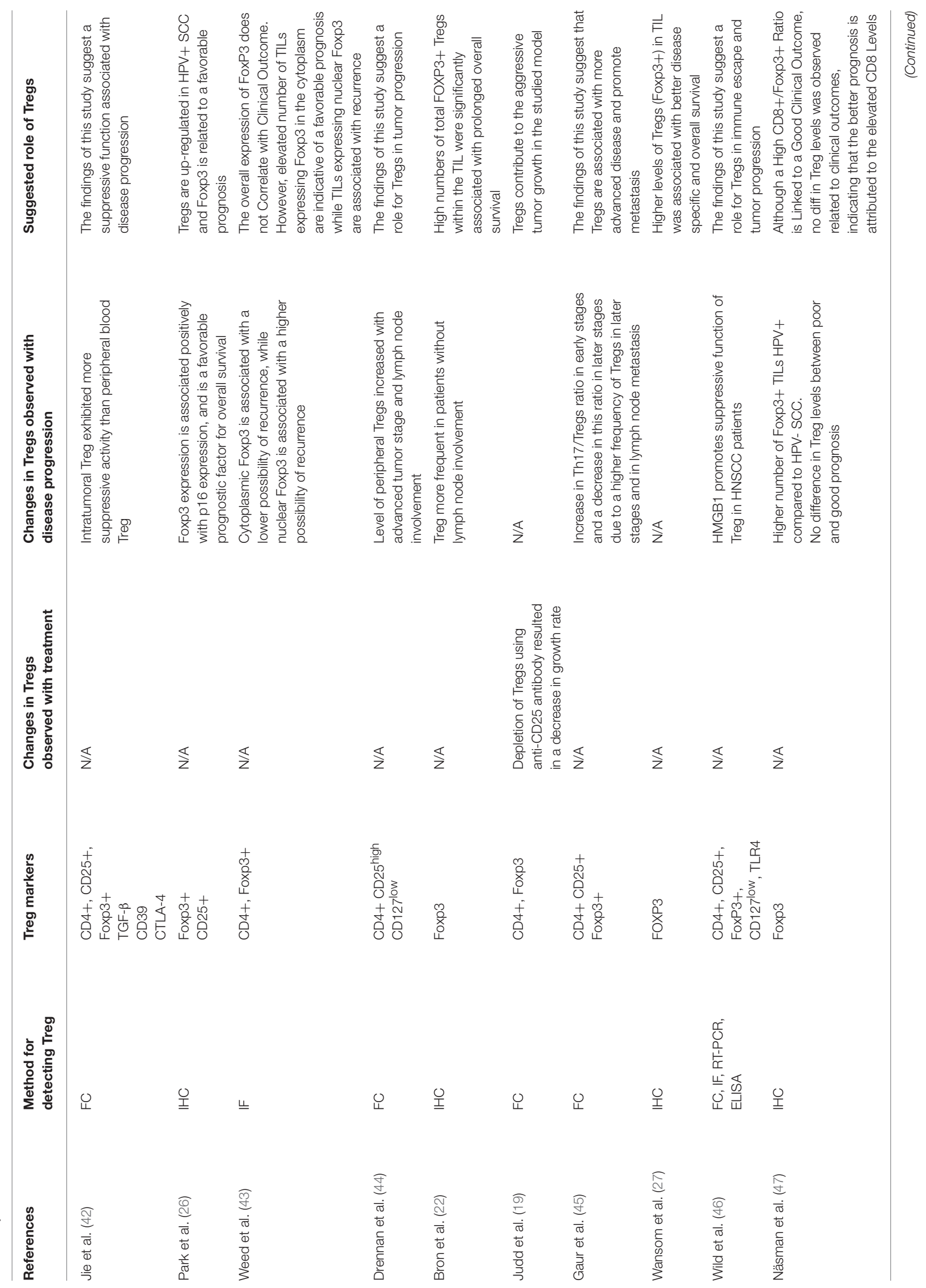




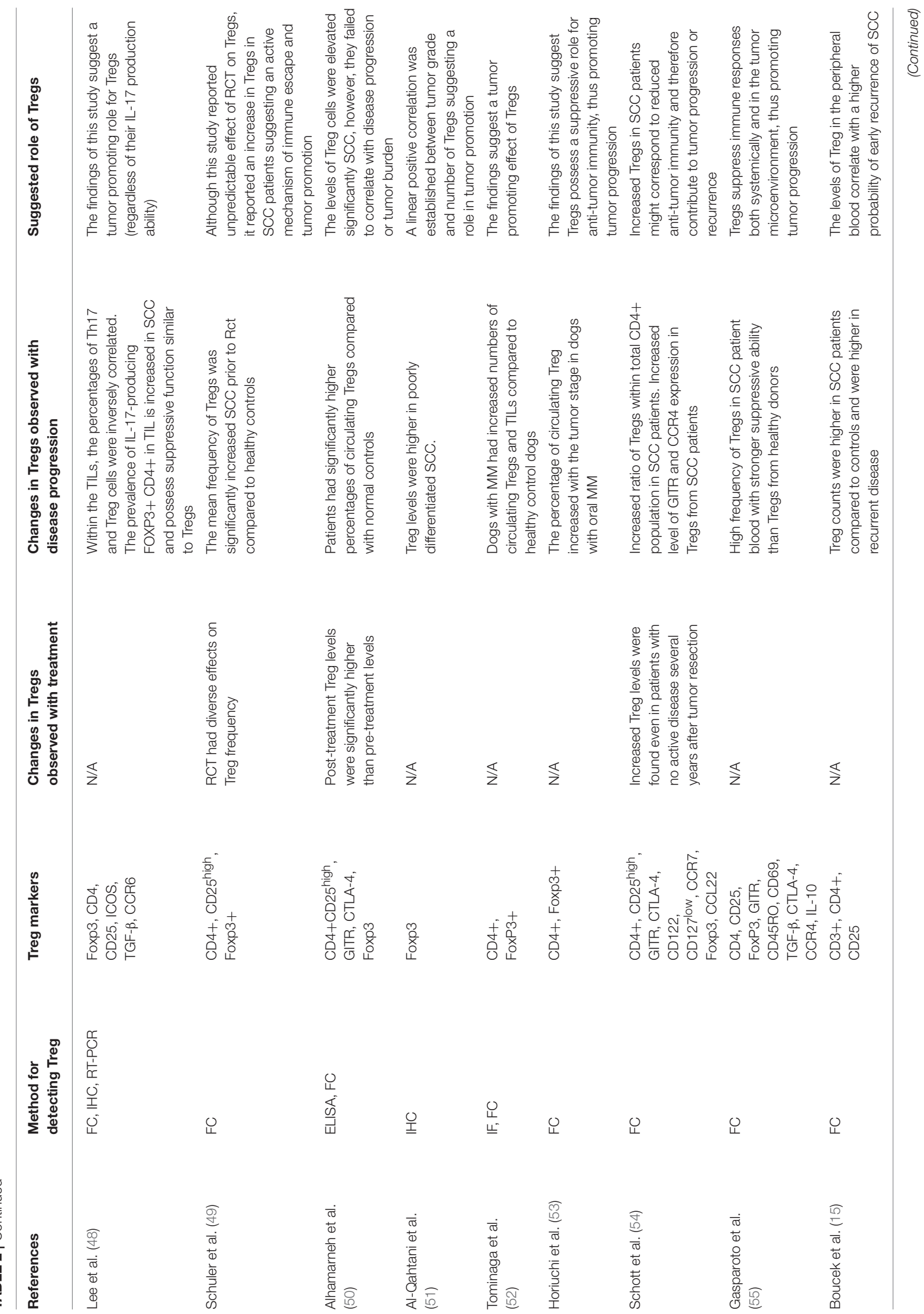




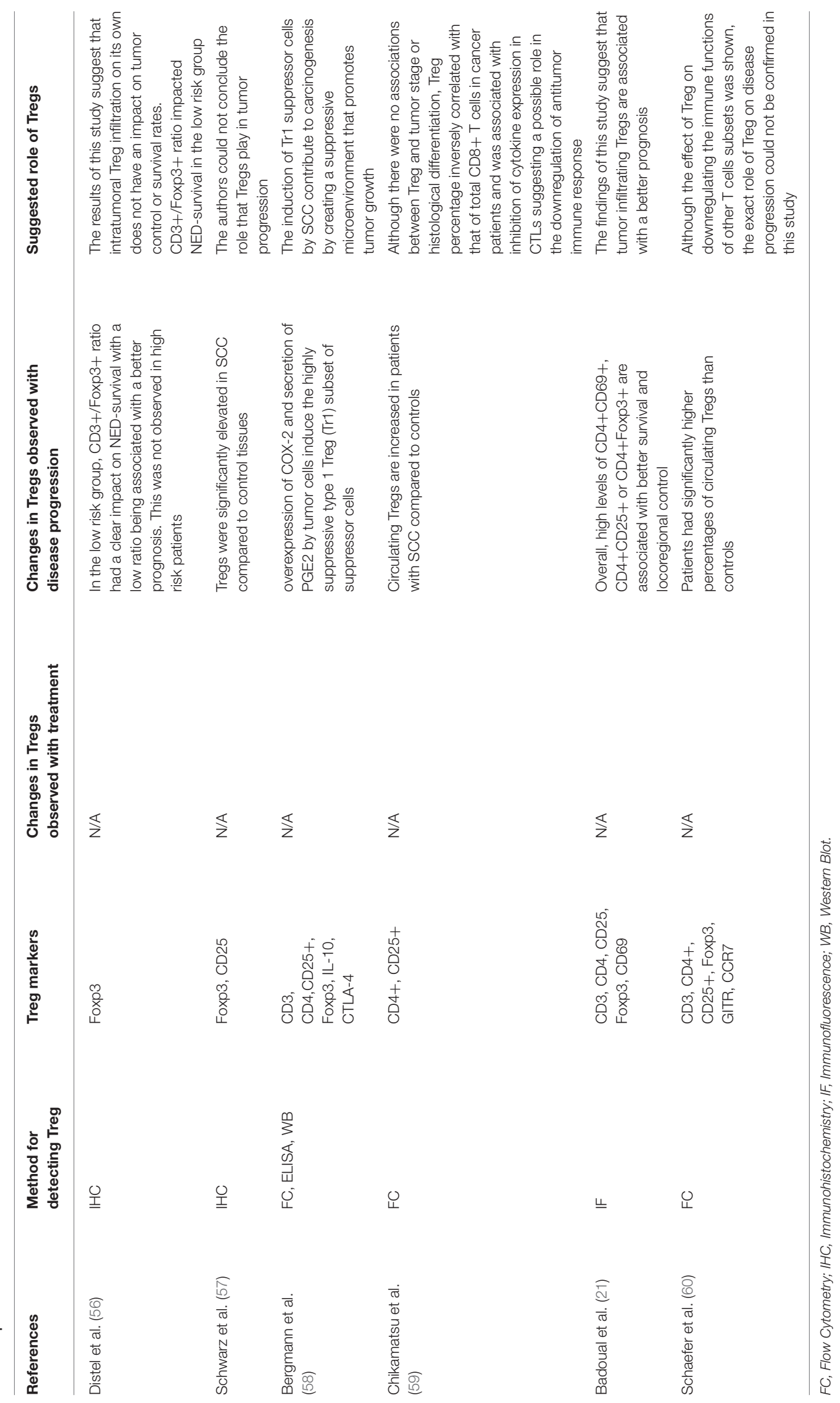


progression $(16,19,20,32,33,40,51)$. Regarding the studies that assessed blood samples only, the majority [11 out of $16(68.7 \%)$ ] reported an association between Tregs and poor outcome (15, $17,37,39,44,45,49,53,54,58,59)$, while three studies reported a good outcome $(23,24,29)$ and two studies could not conclude a definite role $(50,60)$. When both tumor and blood samples were assessed, only two studies (out of 11) could not define a role for Tregs in disease progression $(36,38)$, two studies found a positive correlation with good outcome $(22,27)$ while the remaining seven studies reported a correlation with poor outcome and disease progression $(18,41,42,46,48,52$, $55)$.

Regarding the method used to detect Tregs, interestingly, flow cytometry was only used in two of the nine studies that concluded a good prognosis $(23,24)$, and four out of the studies that made no conclusion $(36,38,50,60)$. On the other hand, immunohistochemistry was used in seven out of the nine studies that found a positive connection between Treg and a better clinical outcome $(22,24-29)$, and seven out of the studies that made no conclusion $(31,34-36,47,56,57)$.

As for the markers used, remarkably, Foxp3 was the only marker used to identify Tregs in five out of the nine studies that suggested a positive clinical outcome with an increase of Tregs $(22,25,27-29)$. Five out of the seven studies that used CTLA-4 as a marker of Treg correlated the presence of Treg with a poor clinical outcome $(18,42,54,55,58)$. The remaining two did not conclude a definitive role for Tregs $(36,50)$. On the other hand, out of the four studies that assessed GITR, two associated Tregs with poor clinical outcome and disease progression $(54,55)$, while the other two did not conclude a role $(50,60)$. All four studies that assessed TGF- $\beta$ as a marker of Treg function found a negative clinical outcome associated with Treg $(18,42,48,55)$.

\section{DISCUSSION}

Cancer immunotherapy to reactivate anti-tumor immunity is one of the most important recent developments in cancer treatment. For some patients, targeting the immune system to boost its anti-tumor activity can generate enduring disease remission, but despite the impressive successes in cancer immunotherapy, the response in patients is sometimes transient. This is attributed to multiple factors including the exhaustion of tumor-specific CD8 $\mathrm{T}$ cells in addition to induced suppression of the immune response against cancer. One of the major immune escape mechanisms in cancer patients is the conversion and dominance of suppressive immune cells within the tumor microenvironment that hamper the function of anti-tumor effector $\mathrm{T}$ cells. Regulatory CD4 T cells (Tregs) are among the most studied suppressor cells in the tumor microenvironment and their role in mediating tumor progression has been reported in many types of cancer. Indeed, reducing the number of Tregs has been reported to enhance anti-tumor immunity and promote tumor regression (9-14).

However, in head and neck cancer and particularly in OPSCC, the role of Tregs in mediating tumor progression and affecting the overall clinical outcome is not clear. In fact, there are conflicting reports in the literature; while a considerable number of studies reported a similar role for Tregs in mediating tumor escape mechanisms and facilitating tumor progression (15-20), other studies reported an opposite role and associated Tregs with a positive clinical outcome (21-29).

In this systematic review, we attempted to assess the body of knowledge available about the role that Tregs play in head and neck cancer with the aim of understanding the reasons for this contradiction in describing the role that Tregs play in disease progression and the clinical outcome.

Our findings emphasized the controversy in the literature. An elevated level of Tregs in patients was observed in some studies $(15,20,23,31-34,37,39-41,44,45,48-55,57,59,60)$, while no significant differences were reported between patients and healthy controls in others and a decrease in Tregs with more advanced disease was observed in three studies $(22,29,35)$. While more than half of the reviewed studies reported a poor prognosis associated with increased levels of Tregs (15-20, 32, 33, 37, 39$42,44-46,48,49,51-55,58,59)$, many studies reported a better prognosis (21-29). A considerable number of studies did not conclude a role for Tregs in tumor progression or clinical outcome $(31,34-36,38,43,47,50,56,57,60)$.

One of the potential reasons for the controversy in the literature, is different reports from different species. We therefore included all the manuscripts from all species to assess whether the species under study affected the reported outcome. The only study that assessed both human and murine samples reported a role for Tregs in promoting tumor progression (32). One of the two studies that assessed murine sample did not reach a conclusion about the role of Tregs (34), while the second murine study reported a role for Tregs in enhancing tumor progression (19). Similar results about the role of Tregs in promoting disease progression were reported in the only study that assessed rat samples (41) and the two canine samples $(52,53)$. These findings ruled out any role for inter-species variability in the controversy in the literature.

In recent years, the incidence of HPV positive oropharyngeal cancers has increased and is on the rise. Surprisingly, we report that HPV status was assessed in only 11 studies out of the 45 included in this systematic review. HPV-associated tumors are a distinct subtype with different intra-tumoral immune cell infiltration and better prognosis $(24,27,28,47)$. Therefore, phenotyping tumors according to their HPV positivity is essential when assessing the role of different immune cells in anti-tumor immunity.

Despite the advances in head and neck cancer diagnosis and treatment, the mortality rate is still high. This is mainly attributed to late diagnosis and the lack of predictors of disease progression. Premalignant lesions are altered tissues that carry a higher risk of developing into malignancy, but unfortunately markers to predict malignant transformation into malignancy in these lesions are lacking. Surprisingly, among all the reviewed articles in this study, only three studies assessed premalignant lesions in animal models $(32,34,41)$, and only one of these studies assessed samples from human patients (32). All three studies reported an increase in suppressive Tregs with disease progression from 
normal through dysplastic to neoplastic lesions $(32,34,41)$. In their study, Ma et al. reported a correlation between disease stage and Tregs and in particular in A2AR expression. They reported that blocking A2AR reduced Tregs in the tumor bearing mice and enhanced anti-tumor immune response (32). Understanding the immune response within premalignant lesions is crucial to predict their progression into malignancy and to design treatments to modulate the immune response to eliminate these lesions before transforming into cancerous lesions.

Interestingly, distinction between thymic vs. peripheral Treg within the tumor microenvironment was not made nor assessed in any of the identified manuscripts in this systematic review. This is not a surprise given the lack of markers that accurately determine the origin of Tregs, but certainly measuring intratumoral numbers of converted Treg, defined by markers such as CD103 or S1PR may yield more precision for the role that Treg play within the tumor microenvironment.

In this systematic review, we found that Foxp3 is the most commonly used marker for Treg identification. In fact, it was the only marker used in 13 studies $(16,20,22,25,27-29,34,35$, $40,47,51,56)$. Many of the studies used immunohistochemistry and a single stain to detect Foxp3. This causes a potential problem as Foxp3 is highly expressed in other activated $\mathrm{T}$ cell subsets including effector $\mathrm{T}$ cells. In fact, it has been proposed that under certain inflammatory condition, Foxp3+ Tregs might become unstable adopting a phenotype that is more characteristic of effector CD4+ T cells (61). Foxp3 might be a marker of activation rather than a marker of regulation and a key identifier of Tregs. Therefore, using dual staining and colocalization of markers such as CD4 and Foxp3 could clarify the role of Treg TIL subset in the tumor microenvironment more accurately.

Furthermore, Foxp3 is expressed in tumor cells. In fact, it has been reported that tongue SCC tumor cells express Foxp3 and its expression significantly associated with disease progression and poor patient outcome (62). The same group found that Foxp3 expressed in tumor cells has distinct biological functions compared with that in Tregs (63). On the other hand, the expression of Foxp3 in tumor cells is associated with an increase in the secretion of SCTLA-4, which was recently reported to be a favorable predictor of clinical outcome in advanced cancers (64). This could explain the reported association between Tregs, as identified by Foxp3 expression, and a favorable clinical outcome.

This adds to the controversy regarding the role of Tregs and emphasizes the need to use more than one method and different markers to detect Tregs within the tumor microenvironment. Remarkably, immunohistochemistry was the only used method to assess Tregs in 21 studies $(16,20,22,24-29,31-36,40$, $47,48,51,56,57)$. A study further suggests that the overall expression of Foxp3 in Tregs by itself is not an important predictor of clinical outcome, but rather the localization of Foxp3 is the important predictor of outcome. Weed et al. reported that in oral SCC, nuclear Foxp3 is associated with a higher probability of early disease recurrence in comparison to cytoplasmic Foxp3, which is associated with a lower probability of recurrence (43). Immune profiling and the pattern of TIL within the tumors is of great importance as reported by Feng et al. after we conducted our search. They reported that the distance between the suppressive Foxp3+ Tregs and the effector $\mathrm{CD} 8+\mathrm{T}$ cells are predictive of patient overall survival (65). Surprisingly, despite the great advances in different assays that added to the confidence in defining Treg markers, our study did not find any major changes in the assays or markers used to detect Tregs over the 12 year period (2005-2017) that the manuscripts included in this review covered. These reports emphasize the importance of using different markers, assays and analyses in the study of immune cells in cancer patients.

Checkpoint inhibitor antibodies represent a novel type of cancer immunotherapy that has seen notable success in the treatment of different cancers (66). One of the major targets of checkpoint inhibitors is CTLA-4, which is highly expressed on Tregs. Only seven studies out of the 45 studies that we assessed looked at the expression of CTLA-4 in Treg or used it as an identifier for these suppressor cells $(18,36,42,50,54$, $55,58)$, five of which correlated the presence of Treg with a poor clinical outcome $(18,42,54,55,58)$. One of these studies reported a higher frequency of CTLA-4+ Tregs (identified as CD4+CD25 ${ }^{\text {hi }}$ Foxp3+) in non-responder patients to Cetuximab (18), suggesting a potential use of this immune checkpoint as a biomarker for response to therapy.

GITR, another immune checkpoint was assessed in four studies as a marker of Treg function $(50,54,55,60)$, two of which associated Tregs with poor clinical outcome and disease progression $(54,55)$. TGF- $\beta$ was assessed in four studies as by the membrane bound form (LAP), or using RT-PCR $(18,42,48,55)$, all of which correlated Tregs to poor clinical outcome.

\section{CONCLUSIONS}

In conclusion, our systematic review emphasized the existing controversy regarding the role of Tregs in head and neck cancer, and in particular in OPSCC. We conclude that similar to most cancer types, Tregs contribute to tumor escape mechanisms and are therefore associated with poor clinical outcome. The inconsistent results reported in the literature could be due to the use of different markers to identify Tregs, variation in patient recruitment criteria or a heterogeneous cancer population. Indeed, we observed major differences in the reported outcomes between studies that assessed tumor samples, and those that assessed blood samples, suggesting the need to assess both to reach a more definitive understanding of the role of different immune cells in disease progression. HPV status, an important prognostic marker in OPSCC, was not assessed in majority of the studies, which could explain some of the discrepancy in the findings.

Our findings therefore suggest the need to define a better and more robust method to detect Tregs in the tumor microenvironment and in the periphery using a combination of methodologies, markers and analyses. We suggest using a combination of markers to define Tregs in the periphery and within TIL, including CD4, CD3, CD25, CD127lo, FoxP3, 
and CTLA-4. We also propose incorporating the regulatory properties of tumor cells as well as TIL for a complete picture of the tumor microenvironment.

\section{AUTHOR CONTRIBUTIONS}

CO performed the search, screening and data extraction. FW contributed to results interpretation and writing the manuscript.

\section{REFERENCES}

1. Thompson LDR. Head and Neck Cancers. Lyon: World Health Organization (2014).

2. Thomas SJ, Penfold CM, Waylen A, Ness AR. The changing aetiology of head and neck squamous cell cancer: a tale of three cancers? Clin Otolaryngol. (2018) 43: 999-1003. doi: 10.1111/coa.13144

3. Cancer-Research-UK. Oral Cancer Mortality Statistics (2017). Available online at: http://www.cancerresearchuk.org/health-professional/cancer-statistics/ statistics-by-cancer-type/oral-cancer/mortality\#heading-Three

4. Couzin-Frankel J. Breakthrough of the year 2013. Cancer immunotherapy. Science (2013) 342:1432-3. doi: 10.1126/science.342.6165.1432

5. Facciabene A, Motz GT, Coukos G. T-regulatory cells: key players in tumor immune escape and angiogenesis. Cancer Res. (2012) 72:2162-71. doi: 10.1158/0008-5472.CAN-11-3687

6. Feuerer M, Hill JA, Mathis D, Benoist C. Foxp3 ${ }^{+}$regulatory T cells: differentiation, specification, subphenotypes. Nat Immunol. (2009) 10:689-95. doi: $10.1038 /$ ni. 1760

7. Tang Q, Bluestone JA. The Foxp $3^{+}$regulatory T cell: a jack of all trades, master of regulation. Nat Immunol. (2008) 9:239-44. doi: 10.1038/ni1572

8. Antony PA, Piccirillo CA, Akpinarli A, Finkelstein SE, Speiss PJ, Surman $\mathrm{DR}$, et al. $\mathrm{CD}^{+} \mathrm{T}$ cell immunity against a tumor/self-antigen is augmented by $\mathrm{CD} 4{ }^{+} \mathrm{T}$ helper cells and hindered by naturally occurring $\mathrm{T}$ regulatory cells. J Immunol. (2005) 174:2591-601. doi: 10.4049/jimmunol.174. 5.2591

9. Jarry U, Donnou S, Vincent $M$, Jeannin P, Pineau L, Fremaux I, et al. Treg depletion followed by intracerebral CpG-ODN injection induce brain tumor rejection. J Neuroimmunol. (2014) 267:35-42. doi: 10.1016/j.jneuroim.2013.12.005

10. Keenan BP, Saenger Y, Kafrouni MI, Leubner A, Lauer P, Maitra A, et al. A listeria vaccine and depletion of T-regulatory cells activate immunity against early stage pancreatic intraepithelial neoplasms and prolong survival of mice. Gastroenterology (2014) 146:1784.e6-94.e6. doi: 10.1053/j.gastro.2014. 02.055

11. Reginato E, Mroz P, Chung H, Kawakubo M, Wolf P, Hamblin MR. Photodynamic therapy plus regulatory T-cell depletion produces immunity against a mouse tumour that expresses a self-antigen. Br J Cancer (2013) 109:2167-74. doi: 10.1038/bjc.2013.580

12. Zhou S, Tao H, Zhen Z, Chen H, Chen G, Yang Y. Depletion of CD4 ${ }^{+} \mathrm{CD} 25^{+}$ regulatory T cells promotes CCL21-mediated antitumor immunity. PLoS ONE (2013) 8:e73952. doi: 10.1371/journal.pone.0073952

13. Mkrtichyan M, Najjar YG, Raulfs EC, Abdalla MY, Samara R, Rotem-Yehudar $\mathrm{R}$, et al. Anti-PD-1 synergizes with cyclophosphamide to induce potent antitumor vaccine effects through novel mechanisms. Eur J Immunol. (2011) 41:2977-86. doi: 10.1002/eji.201141639

14. Abu-Eid R, Samara RN, Ozbun L, Abdalla MY, Berzofsky JA, Friedman $\mathrm{KM}$, et al. Selective inhibition of regulatory $\mathrm{T}$ cells by targeting the PI3K-Akt pathway. Cancer Immunol Res. (2014) 2:1080-1089. doi: 10.1158/2326-6066.CIR-14-0095

15. Boucek J, Mrkvan T, Chovanec M, Kuchar M, Betka J, Boucek V, et al. Regulatory $\mathrm{T}$ cells and their prognostic value for patients with squamous cell carcinoma of the head and neck. J Cell Mol Med. (2010) 14:426-33. doi: 10.1111/j.1582-4934.2008.00650.x

16. Hanakawa H, Orita Y, Sato Y, Takeuchi M, Ohno K, Gion Y, et al. Regulatory $\mathrm{T}$-cell infiltration in tongue squamous cell carcinoma.
RA designed the study, checked the accuracy of the data extraction, and contributed to results interpretation and writing the manuscript.

\section{FUNDING}

CO was supported by an Innes Will Scholarship, University of Aberdeen HotStart Summer Scholarship Scheme.

Acta Otolaryngol. (2014) 134:859-64. doi: 10.3109/00016489.2014. 918279

17. Ihara F, Sakurai D, Horinaka A, Makita Y, Fujikawa A, Sakurai T, et al. CD45RA(-)Foxp3(high) regulatory $\mathrm{T}$ cells have a negative impact on the clinical outcome of head and neck squamous cell carcinoma. Cancer Immunol Immunother. (2017) 66:1275-85. doi: 10.1007/s00262-0172021-z

18. Jie HB, Schuler PJ, Lee SC, Srivastava RM, Argiris A, Ferrone S, et al. CTLA$4^{+}$regulatory $\mathrm{T}$ cells increased in cetuximab-treated head and neck cancer patients suppress NK cell cytotoxicity and correlate with poor prognosis. Cancer Res. (2015) 75:2200-10. doi: 10.1158/0008-5472.CAN-14-2788

19. Judd NP, Allen CT, Winkler AE, Uppaluri R. Comparative analysis of tumor-infiltrating lymphocytes in a syngeneic mouse model of oral cancer. Otolaryngol Head Neck Surg. (2012) 147:493-500. doi: $10.1177 / 0194599812442037$

20. Stasikowska-Kanicka O, Wagrowska-Danilewicz M, Danilewicz M. Immunohistochemical analysis of $\mathrm{Foxp}^{+}, \mathrm{CD} 4^{+}, \mathrm{CD} 8^{+}$cell infiltrates and PD-L1 in oral squamous cell carcinoma. Pathol Oncol Res (2017) 24, 497-505. doi: 10.1007/s12253-017-0270-y

21. Badoual C, Hans S, Rodriguez J, Peyrard S, Klein C, Agueznay Nel H, et al. Prognostic value of tumor-infiltrating $\mathrm{CD} 4^{+}$T-cell subpopulations in head and neck cancers. Clin Cancer Res. (2006) 12:465-72. doi: 10.1158/1078-0432.CCR-05-1886

22. Bron L, Jandus C, Andrejevic-Blant S, Speiser DE, Monnier P, Romero P, et al. Prognostic value of arginase-II expression and regulatory T-cell infiltration in head and neck squamous cell carcinoma. Int J Cancer (2013) 132:E85-93. doi: $10.1002 /$ ijc. 27728

23. Lim KP, Chun NA, Ismail SM, Abraham MT, Yusoff MN, Zain RB, et al. $\mathrm{CD} 4{ }^{+} \mathrm{CD} 25 \mathrm{hiCD} 127$ low regulatory $\mathrm{T}$ cells are increased in oral squamous cell carcinoma patients. PLoS ONE (2014) 9:e103975. doi: 10.1371/journal.pone. 0103975

24. Lukesova E, Boucek J, Rotnaglova E, Salakova M, Koslabova E, Grega M, et al. High level of Tregs is a positive prognostic marker in patients with HPVpositive oral and oropharyngeal squamous cell carcinomas. Biomed Res Int. (2014) 2014:303929. doi: 10.1155/2014/303929

25. Nguyen N, Bellile E, Thomas D, McHugh J, Rozek L, Virani S, et al. Tumor infiltrating lymphocytes and survival in patients with head and neck squamous cell carcinoma. Head Neck (2016) 38:1074-84. doi: 10.1002/hed.24406

26. Park K, Cho KJ, Lee M, Yoon DH, Kim SB. Importance of FOXP3 in prognosis and its relationship with p16 in tonsillar squamous cell carcinoma. Anticancer Res. (2013) 33:5667-73.

27. Wansom D, Light E, Thomas D, Worden F, Prince M, Urba S, et al. Infiltrating lymphocytes and human papillomavirus-16-associated oropharyngeal cancer. Laryngoscope (2012) 122:121-7. doi: 10.1002/lary.22133

28. Ward MJ, Thirdborough SM, Mellows T, Riley C, Harris S, Suchak $\mathrm{K}$, et al. Tumour-infiltrating lymphocytes predict for outcome in HPV-positive oropharyngeal cancer. Br J Cancer (2014) 110:489-500. doi: 10.1038/bjc.2013.639

29. Wolf GT, Chepeha DB, Bellile E, Nguyen A, Thomas D, McHugh J, et al. Tumor infiltrating lymphocytes (TIL) and prognosis in oral cavity squamous carcinoma: a preliminary study. Oral Oncol. (2015) 51:90-5. doi: 10.1016/j.oraloncology.2014.09.006

30. Moher D, Liberati A, Tetzlaff J, Altman DG, Group P. Preferred reporting items for systematic reviews and meta-analyses: the PRISMA 
statement. J Clin Epidemiol. (2009) 62:1006-12. doi: 10.1016/j.jclinepi.2009. 06.005

31. Hussaini HM, Parachuru VPB, Seymour GJ, Rich AM. Forkhead box-P3 ${ }^{+}$regulatory $\mathrm{T}$ cells and toll-like receptor 2 co-expression in oral squamous cell carcinoma. Acta Histochem. (2017) 119:205-10. doi: 10.1016/j.acthis.2016.12.005

32. Ma SR, Deng WW, Liu JF, Mao L, Yu GT, Bu LL, et al. Blockade of adenosine $\mathrm{A} 2 \mathrm{~A}$ receptor enhances $\mathrm{CD} 8^{+} \mathrm{T}$ cells response and decreases regulatory $\mathrm{T}$ cells in head and neck squamous cell carcinoma. Mol Cancer (2017) 16:99. doi: 10.1186/s12943-017-0665-0

33. Zhou X, Su YX, Lao XM, Liang YJ, Liao GQ. CD19+ $\mathrm{IL}-10^{+}$regulatory $\mathrm{B}$ cells affect survival of tongue squamous cell carcinoma patients and induce resting $\mathrm{CD}^{+} \mathrm{T}$ cells to $\mathrm{CD}^{+}{ }^{+}$Foxp3 $^{+}$regulatory $\mathrm{T}$ cells. Oral Oncol. (2016) 53:27-35. doi: 10.1016/j.oraloncology.2015. 11.003

34. Miki K, Orita Y, Gion Y, Takao S, Ohno K, Takeuchi M, et al. Regulatory T cells function at the early stage of tumor progression in a mouse model of tongue squamous cell carcinoma. Cancer Immunol Immunother. (2016) 65:1401-10. doi: 10.1007/s00262-016-1902-x

35. da Cunha Filho FAP, Aguiar MC, Souza LB, Pinto LP, Godoy GP, Alves $\mathrm{PM}$, et al. Immunohistochemical analysis of $\mathrm{FoxP}^{+}$regulatory $\mathrm{T}$ cells in lower lip squamous cell carcinomas. Braz Oral Res (2016) 30:e130. doi: 10.1590/1807-3107bor-2016.vol30.0130

36. Montler R, Bell RB, Thalhofer C, Leidner R, Feng Z, Fox BA, et al. OX40, PD- 1 and CTLA-4 are selectively expressed on tumor-infiltrating $\mathrm{T}$ cells in head and neck cancer. Clin Transl Immunol. (2016) 5:e70. doi: 10.1038/cti. 2016.16

37. Takahashi H, Sakakura K, Mito I, Ida S, Chikamatsu K. Dynamic changes in immune cell profile in head and neck squamous cell carcinoma: immunomodulatory effects of chemotherapy. Cancer Sci (2016) 107:1065-71. doi: $10.1111 /$ cas. 12976

38. Partlova S, Boucek J, Kloudova K, Lukesova E, Zabrodsky M, Grega $\mathrm{M}$, et al. Distinct patterns of intratumoral immune cell infiltrates in patients with HPV-associated compared to non-virally induced head and neck squamous cell carcinoma. Oncoimmunology (2015) 4:e965570. doi: $10.4161 / 21624011.2014 .965570$

39. Sun W, Li WJ, Wu CY, Zhong H, Wen WP. CD45RA-Foxp $3^{\text {high }}$ but not CD45RA ${ }^{+}$Foxp $3^{\text {low }}$ suppressive $\mathrm{T}$ regulatory cells increased in the peripheral circulation of patients with head and neck squamous cell carcinoma and correlated with tumor progression. J Exp Clin Cancer Res. (2014) 33:35. doi: 10.1186/1756-9966-33-35

40. Schipmann S, Wermker K, Schulze HJ, Kleinheinz J, Brunner G. Cutaneous and oral squamous cell carcinoma-dual immunosuppression via recruitment of $\mathrm{FOXP}^{+}$regulatory T cells and endogenous tumour FOXP3 expression? J Craniomaxillofac Surg. (2014) 42:1827-33. doi: 10.1016/j.jcms.2014. 06.022

41. Zhao J, Wang Z, Han J, Qiu X, Pan J, Chen J. Increased frequency of CD4 ${ }^{+}$ $\mathrm{CD}_{2}{ }^{+} \mathrm{FOXP}^{+}$cells correlates with the progression of 4-nitroquinoline1oxide-induced rat tongue carcinogenesis. Clin Oral Investig. (2014) 18:172530. doi: 10.1007/s00784-013-1146-5

42. Jie HB, Gildener-Leapman N, Li J, Srivastava RM, Gibson SP, Whiteside $\mathrm{TL}$, et al. Intratumoral regulatory $\mathrm{T}$ cells upregulate immunosuppressive molecules in head and neck cancer patients. Br J Cancer (2013) 109:2629-35. doi: $10.1038 /$ bjc. 2013.645

43. Weed DT, Walker G, De La Fuente AC, Nazarian R, Vella JL, Gomez-Fernandez CR, et al. FOXP3 subcellular localization predicts recurrence in oral squamous cell carcinoma. PLOS ONE (2013) 8:e71908. doi: 10.1371/journal.pone.0071908

44. Drennan S, Stafford ND, Greenman J, Green VL. Increased frequency and suppressive activity of CD127(low/-) regulatory $\mathrm{T}$ cells in the peripheral circulation of patients with head and neck squamous cell carcinoma are associated with advanced stage and nodal involvement. Immunology (2013) 140:335-43. doi: 10.1111/imm.12144

45. Gaur P, Qadir GA, Upadhyay S, Singh AK, Shukla NK, Das SN. Skewed immunological balance between Th17 $\left(\mathrm{CD} 4^{+} \mathrm{IL} 17 \mathrm{~A}{ }^{+}\right)$and Treg $\left(\mathrm{CD} 4{ }^{+} \mathrm{CD} 25^{+}\right.$FOXP3 $\left.{ }^{+}\right)$cells in human oral squamous cell carcinoma. Cell Oncol. (2012) 35:335-43. doi: 10.1007/s13402-0120093-5
46. Wild CA, Brandau S, Lotfi R, Mattheis S, Gu X, Lang S, et al. HMGB1 is overexpressed in tumor cells and promotes activity of regulatory $T$ cells in patients with head and neck cancer. Oral Oncol (2012) 48:409-16. doi: 10.1016/j.oraloncology.2011.12.009

47. Näsman A, Romanitan M, Nordfors C, Grun N, Johansson H, Hammarstedt L, et al. Tumor infiltrating $\mathrm{CD}^{+}$and Foxp $3^{+}$lymphocytes correlate to clinical outcome and human papillomavirus (HPV) status in tonsillar cancer. PLoS ONE (2012) 7:e38711. doi: 10.1371/journal.pone.0038711

48. Lee JJ, Chang YL, Lai WL, Ko JY, Kuo MY, Chiang CP, et al. Increased prevalence of interleukin-17-producing $\mathrm{CD}^{+}$tumor infiltrating lymphocytes in human oral squamous cell carcinoma. Head Neck (2011) 33:1301-8. doi: 10.1002/hed.21607

49. Schuler PJ, Borger V, Bolke E, Habermehl D, Matuschek C, Wild CA, et al. Dendritic cell generation and $\mathrm{CD} 4{ }^{+} \mathrm{CD} 25$ high $\mathrm{FOXP}^{+}$regulatory t cells in human head and neck carcinoma during radio-chemotherapy. Eur J Med Res. (2011) 16:57-62. doi: 10.1186/2047-783X-16-2-57

50. Alhamarneh O, Agada F, Madden L, Stafford N, Greenman J. Serum IL10 and circulating $\mathrm{CD}^{+} \mathrm{CD} 25$ (high) regulatory $\mathrm{T}$ cell numbers as predictors of clinical outcome and survival in patients with head and neck squamous cell carcinoma. Head Neck (2011) 33:415-23. doi: 10.1002/hed. 21464

51. Al-Qahtani D, Anil S, Rajendran R. Tumour infiltrating $\mathrm{CD}_{2} 5^{+} \mathrm{FoxP}^{+}$ regulatory $\mathrm{T}$ cells (Tregs) relate to tumour grade and stromal inflammation in oral squamous cell carcinoma. J Oral Pathol Med. (2011) 40:636-42. doi: 10.1111/j.1600-0714.2011.01020.x

52. Tominaga M, Horiuchi Y, Ichikawa M, Yamashita M, Okano K, Jikumaru $\mathrm{Y}$, et al. Flow cytometric analysis of peripheral blood and tumorinfiltrating regulatory $\mathrm{T}$ cells in dogs with oral malignant melanoma. $J$ Vet Diagn Invest. (2010) 22:438-41. doi: 10.1177/1040638710022 00317

53. Horiuchi Y, Tominaga M, Ichikawa M, Yamashita M, Okano K, Jikumaru $\mathrm{Y}$, et al. Relationship between regulatory and type $1 \mathrm{~T}$ cells in dogs with oral malignant melanoma. Microbiol Immunol. (2010) 54:152-9. doi: 10.1111/j.1348-0421.2009.00194.x

54. Schott AK, Pries R, Wollenberg B. Permanent up-regulation of regulatory Tlymphocytes in patients with head and neck cancer. Int J Mol Med. (2010) 26:67-75. doi: 10.3892/ijmm_00000436

55. Gasparoto TH, de Souza Malaspina TS, Benevides L, de Melo EJ, Jr, Costa MR, Damante JH, et al. Patients with oral squamous cell carcinoma are characterized by increased frequency of suppressive regulatory $\mathrm{T}$ cells in the blood and tumor microenvironment. Cancer Immunol Immunother. (2010) 59:819-28. doi: 10.1007/s00262-0090803-7

56. Distel LV, Fickenscher R, Dietel K, Hung A, Iro H, Zenk J, et al. Tumour infiltrating lymphocytes in squamous cell carcinoma of the oro- and hypopharynx: prognostic impact may depend on type of treatment and stage of disease. Oral Oncol. (2009) 45:e167-74. doi: 10.1016/j.oraloncology.2009.05.640

57. Schwarz S, Butz M, Morsczeck C, Reichert TE, Driemel O. Increased number of CD25 FoxP3 regulatory $\mathrm{T}$ cells in oral squamous cell carcinomas detected by chromogenic immunohistochemical double staining. J Oral Pathol Med. (2008) 37:485-9. doi: 10.1111/j.1600-0714.2008. 00641.x

58. Bergmann C, Strauss L, Zeidler R, Lang S, Whiteside TL. Expansion of human $\mathrm{T}$ regulatory type 1 cells in the microenvironment of cyclooxygenase 2 overexpressing head and neck squamous cell carcinoma. Cancer Res (2007) 67:8865-73. doi: 10.1158/0008-5472.CAN-07-0767

59. Chikamatsu K, Sakakura K, Whiteside TL, Furuya N. Relationships between regulatory $\mathrm{T}$ cells and $\mathrm{CD}^{+}$effector populations in patients with squamous cell carcinoma of the head and neck. Head Neck (2007) 29:120-7. doi: 10.1002/hed.20490

60. Schaefer C, Kim GG, Albers A, Hoermann K, Myers EN, Whiteside TL. Characteristics of $\mathrm{CD} 4{ }^{+} \mathrm{CD} 25^{+}$regulatory $\mathrm{T}$ cells in the peripheral circulation of patients with head and neck cancer. Br J Cancer (2005) 92:913-20. doi: $10.1038 /$ sj.bjc. 6602407

61. Sakaguchi S, Vignali DAA, Rudensky AY, Niec RE, Waldmann H. The plasticity and stability of regulatory T cells. Nat. Rev. Immunol. (2013) 13:4617. doi: $10.1038 /$ nri3464 
62. Liang YJ, Liu HC, Su YX, Zhang TH, Chu M, Liang LZ, et al. Foxp3 expressed by tongue squamous cell carcinoma cells correlates with clinicopathologic features and overall survival in tongue squamous cell carcinoma patients. Oral Oncol. (2011) 47:566-70. doi: 10.1016/j.oraloncology.2011. 04.017

63. Liang YJ, Lao XM, Liang LZ, Liao GQ. Genome-wide analysis of cancer cellderived Foxp3 target genes in human tongue squamous cell carcinoma cells. Int J Oncol. (2015) 46:1935-43. doi: 10.3892/ijo.2015.2926

64. Liu Q, Hu P, Deng G, Zhang J, Liang N, Xie J, et al. Soluble cytotoxic T-lymphocyte antigen 4: a favorable predictor in malignant tumors after therapy. Onco Targets Ther. (2017) 10:2147-54. doi: 10.2147/OTT. S128451

65. Feng Z, Bethmann D, Kappler M, Ballesteros-Merino C, Eckert A, Bell RB, et al. Multiparametric immune profiling in HPV- oral squamous cell cancer. JCI Insight. (2017) 2:93652. doi: 10.1172/jci.insight.93652
66. Brunet JF, Denizot F, Luciani MF, Roux-Dosseto M, Suzan M, Mattei MG, et al. A new member of the immunoglobulin superfamily-CTLA-4. Nature (1987) 328:267-70. doi: $10.1038 / 328267 \mathrm{a} 0$

Conflict of Interest Statement: The authors declare that the research was conducted in the absence of any commercial or financial relationships that could be construed as a potential conflict of interest.

Copyright $\odot 2018$ O'Higgins, Ward and Abu Eid. This is an open-access article distributed under the terms of the Creative Commons Attribution License (CC BY). The use, distribution or reproduction in other forums is permitted, provided the original author(s) and the copyright owner(s) are credited and that the original publication in this journal is cited, in accordance with accepted academic practice. No use, distribution or reproduction is permitted which does not comply with these terms. 